\title{
OPTIMALISASI APLIKASI SURAT MENYURAT PADA PT. BPR SENTRAL MITRA SEJAHTERA (SMS) SUNGAILIAT
}

\author{
Melati Suci Mayasari \\ Program Studi Manajemen Informatika \\ STMIK Atma Luhur \\ Email: imeal_melati@atmaluhur.ac.id \\ Yuyi Andrika \\ Program Studi Sistem Informasi \\ STMIK Atma Luhur \\ Email: yuyiandrika@atmaluhur.ac.id \\ Email: zailunza@gmail.com \\ Fitriyani \\ Program Studi Sistem Informasi \\ STMIK Atma Luhur \\ Email: bilalzakwan12@yahoo.com \\ Zailun \\ Program Studi Sistem Informasi \\ STMIK Atma Luhur \\ Email: zailunza@gmail.com
}

\begin{abstract}
ABSTRAK
PT. BPR Sentral Mitra Sejahtera (SMS) Sungailiat yang beralamat Jln. Nelayan 1 No 80 Sungailiat bergerak dalam bidang financial, yang mana menemui beberapa kendala dalam administrasi surat menyurat yang masih menggunakan buku. Dilihat dari proses administrasi surat menyurat yang ada ternyata sejauh ini menemukan permasalahan seperti pengelolaan surat masuk, pendisposisian, surat keluar, surat penugasan yang belum tersistem secara komputerisasi. Sehingga administrasi surat menyurat tiak efektif, tidak efisien dan kurang rapi. Oleh karena itu dibangun dan dirancanglah suatu optimalisasi sistem adminitrasi surat menyurat yang sudah berbasis komputerisasi. Adapun Metode yang digunakan yaitu Metode OOAD, sedangkan tools pengembangan sistem menggunakan UML, serta model waterfall. Dengan mengoptimalisasi sistem informasi administrasi surat menyurat yang berbasis komputerisasi, semua permasalahan yang dihadapi dapat teratasi, sehingga administrasi surat menyurat menjadi lebih efektif dan efisien.
\end{abstract}

Kata kunci: optimalisasi; surat menyurat; sistem; informasi; aplikasi.

\section{ABSTRACT}

PT. BPR Sentral Mitra Sejahtera (SMS) Sungailiat having the address at Jln. Fisherman 1 No. 80 Sungailiat is engaged in the financial sector, which encounters several obstacles in the administration of correspondence that still uses books. Judging from the administration process of existing correspondence, it turns out that so far there have been problems such as the management of incoming letters, dissemination, outgoing letters, assignment letters that have not been computerized. So that the administration of correspondence is ineffective, inefficient and less tidy. Therefore it was built and designed an optimization of a computerized administrative system of correspondence. The method used is the OOAD Method, while the system development tools use UML, and the Waterfall model. By optimizing the computerized administration of correspondence information systems, all problems encountered can be overcome, so that the administration of correspondence becomes more effective and efficient.

Keywords: optimization; correspondence; system; information; application. 


\section{PENDAHULUAN}

Surat menyurat merupakan kegiatan yang sangat penting dalam mengelola sistem administrasi pada sebuat organisasi dan perusahanan. Mulai dari administasi surat masuk, surat keluar, surat disposisi, maupun surat penugasan. PT. BPR Sentral Mitra Sejahtera yang beralamat Jln. Nelayan 1 No 80 Sungailiat merupakan salah satu perusahaan financial yang masih menerapkan administrasi surat menyurat yang masih manual, sehingga menemui beberapa kendala yaitu membuat pekerjaan menjadi kurang efisien,lambat dan kurang rapinya sistem administrasi surat menyurat. Staff Administasi Surat menyurat merasa kebingungan dalam melaporkan dan membuat laporan surat menyurat.

Dengan memanfaatkan teknologi informasi, penulis melakukan penelitian dengan judul "Optimalisasi Sistem Informasi Surat Menyurat Pada PT. BPR Sentral Mitra Sejahtera Sungailiat”. Dengan ini admnistrasi surat menyurat dapat dilakukan secara komputerisasi sehingga pekerjaan staff administrasi surat menyurat menjadi lebih efektif dan efesien, serta menghasilkan informasi yang sangat berkualitas dan terjamin

\section{METODOLOGI PENELITIAN}

\subsection{Metodologi Penelitian}

Metode yang digunakan adalahmetode OOAD (Object Oriented Analysis and Design). Dengan metode ini, pengembang sistem dapat dengan mudah melakukan maintance terhadap objek-objek penelitian dan pengembangan sistem. Untuk melakukan metode berorientasi objek peneliti melakukan studi pustaka melalui studi kepustakaan, browsing, jurnal yang berkaitan dengan metode ini.

\subsection{Model Pengembangan Sistem}

Model pengembangan sistem yang digunakan dalam penelitian ini adalah model waterfall. Model ini sangat sederhana karena Siklusnya atw System Development Livfe Cyclenya terdiri dari 4 tahapan utama, seperti Planning, Analysis, Design, dan Implementation. Adapun langkah-langkah pada tiap tahap adalah :

\subsubsection{Tahap Perencanaan}

Pada tahap ini dilakukan pengumpulan kebutuhan data dan informasi, antara lain dengan :

a. Observasi; Dengan pengamatan langsung pada kegiatan yang sedang berjalan pada PT. BPR Sentral Mitra Sejahtera (SMS) Sungailiat.

b. Wawancara/interview; Bertanya langsung dan bertukar pikiran kepada para staff di PT. BPR Sentral Mitra Sejahtera agar diketahui dengan jelas kekurangan, permasalahan, dan kebutuhan yang harus dipenuhi demi perbaikan sistem berjalan.

c. Studi Kepustakaan; Membaca jurnal, buku, literatur, dan materi lainnya di internet yang mendukung materi penelitian.

\subsubsection{Analisis Sistem}

Dalam tahapan analisis sistem, menggunakan Diagram Aktifitas (Activity Diagram) dan Diagram Fungsional (Use Case Diagram). Diagram Aktifitas menggambarkan alur/urutan kegiatan dalam proses bisnis. Sedangkan Diagram Fungsional ialah model kebutuhan baru sebuah sistem yang akan dikembangkan.

\subsubsection{Perancangan Sistem}

Dalam rancangan basis data aplikasi sistem informasi adalah sebagai berikut ini : Diagram Keterhubungan Entitas (Entity Relationship Diagram/ERD), Logical Record Structure (LRS), Tabel, Rancangan Layar.

\subsection{Alat Bantu Pengembangan Sistem}

Tools yang digunakan dalam pengembangan sistem adalah UML (Unified Modeling Language) dengan beberapa diagram, tetapi cuma beberapa diagram saja yang digunakan yaitu Diagram Aktifitas (Activity Diagram). 


\subsection{Tinjauan Pustaka}

Beberapa penelitian sebelumnya yang pernah dilakukan yang dijadikan sebagai bahan referensi dalam penelitian ini adalah sebagai berikut :

a. Menurut hasil penelitian Masriadi [1], Tujuan dari penelitian ini menghasilkan rancangan sistem informasi pembuatan surat menyurat yang dapat membantu Andalusia Library And Knowlegde Center dalam mengatasi proses pembuatan surat menyurat yang masih manual. Sehingga diperlukan system yang baru untuk memperbaiki sistem yang.

b. Fera Nita [2] dalam penelitiannya menyimpulkan dengan database penyimpanan data surat masuk, disposisi, dan surat keluar dapat mempercepat kerja biro rektorat, karena data surat masuk dan surat keluar tidak perlu direkam atau ditulis kedalam buku surat.

c. Berdasarkan penelitian Muhammad Fajri dan Lusi Fajarita [3], penelitian yang membahas tentang sistem informasi administrasi surat menyurat pada Kesekretariatan BadanEksekutif Mahasiswa Universitas Budi Luhur(BEM), dimana masalah yang terjadi yaitu masih menggunakan pencatatan manual sehingga masih memerlukan waktu yang cukup lama dalam pendataan surat dan pembuatan laporan mengenai LPJ(Laporan Pertanggungjawaban) kegiatan yang masuk. Sehingga untuk mengatasi permasalahan dilakukan analisa dan perancangan aplikasi menggunakan pendekatan berorientasi obyek. Aplikasi tersebut dikembangkan dengan tools Microsoft VB 2008 dan didukung dengan database MySQL. Tujuan penelitian ini adalah sebuah aplikasi berbasis desktop yang dapat mempermudah dalam proses surat menyurat, mempermudah dalam pembuatan laporan serta penyimpanan data yang lebih baik.

d. Menurut penelitian Okta, Dkk [4], Berdasarkan penelitian yang telah dilakukan oleh peneliti Sistem Informasi Korespondensi Administrasi Layanan tingkat desa dalam rangka meningkatkan kualitas layanan bagi penduduk desa. Adapun Manfaat dari penelitian ini diharapkan dapat membantu menyederhanakan proses layanan korespondensi tempat tinggal di tingkat desa. Pada penelitian ini yang digunakan untuk merancang sistem informasi surat ini adalah SDLC (System Development Life Cycle). diharapkan dengan hadirnya Sistem Informasi Administrasi Administrasi Korespondensi, proses Administrasi Korespondensi dapat berjalan lebih cepat, tepat dan efektif, pengaturan laporan korespondensi dapat dilakukan dengan lebih cepat, menyeluruh dan rapi

e. Penelitian oleh Ericson, Effiyaldi [5] ini bertujuan untuk membentuk sistem informasi administrasi disposisi surat berbasis web pada Dinas Pekerjaan Umum dan Perumahan Rakyat Provinsi Jambi. Dimana penelitian ini menghasilkan rancangan dan menganalisa system yang menggambarkan disposisi surat dengan model pengembangan system yang digunakan adalah Unified Modeling Language yakni use case diagram.

f. Berdasarkan penelitian Endang, Eka, dan Handoko [6], Pengeloalaan Surat bidang humas tidak terlepas saat ini masih manual, yaitu surat masuk dan surat keluar dicatat dalam bentuk buku sehingga cepat tanggap. Dengan adanya Sistem Informasi E-Office pengelolaan surat menyurat menjadi lebih efektif, responsive, dan efisien.

g. Defi Anggraini dan Siska Iriani [7] dalam penelitiannya pengelolaan pengarsipan surat menyurat masih manual. Sehingga diperlukan system informasi pengarsipan surat menyurat dengan menggunakan metodologi Penelitian yaitu Model Waterfall, dan Metode pengumpulan data yaitu metode berorientasi objek.

h. Dalam penelitian Ariana [8] ini membahas proses administrasi surat menyurat Kantor Camat masih manual sehingga tidah efektif dan efisien., menimbulkan berbagai. Sehingga dibangunlah sistem informasi berbasis webyang dapat mempermudah adminstrasi surat menyurat di Kantor Camat Gianyar.

i. Penelitian Agus Dendi dan Datia [9] memaparkan tentang administrasi susrat menyurat yang berjalan masih manual kemudian diganti ke system yang sudah terkomputerisasi. Metode yang digunakan yaitu analisa dan perancangan berorientasi objek, denganmodel Waterfall serta alat bantu/tools yang digunakan adalah UML.

j. Irfan [10] Berdasarkan penelitian dan pengamatan yang dilakukan telah disimpulkan bahwa perancangan yang diusulkan oleh penulis dapat membantu warga dalam melakukan administrasi surat menyurat Kelurahan Deli Tua dan adanya sistem basis data pada konsep penyimpanan surat menyurat pada kantor kelurahan Deli Tua akan mempermudah proses manajemen file khususnya kemudahan dalam proses pencarian file yang telah lama, hal ini juga akan mempermudah kinerja petugas Kelurahan. 


\section{HASIL DAN PEMBAHASAN}

Pembahasan ini menjabarkan tentang proses bisnis pada sistem berjalan dan proses-proses apa saja yang akan diusulkan pada Optimalisasi Sistem Informasi Surat Menyurat Pada PT. BPR Sentral Mitra Sejahtera(SMS) Sungailiat, yang dituangkan dalam Diagram Aktifitas (Activity Diagram) dan Diagram Fungsional (Use Case Diagram), kemudian menampilkan contoh dari beberapa aplikasi sistem informasi tersebut dalam bentuk gambar rancangan layar, serta menjelaskan analisa data dengan Diagram Keterhubungan Entitas (Entity Relationship Diagram/ERD), transformasi ERD ke LRS, LRS, dan tabeltabel yang dihasilkan. Sehingga dari penjabaran tersebut dihasilkan bentuk Optimalisasi Sistem Informasi Surat Menyurat Pada PT. BPR Sentral Mitra Sejahtera(SMS) Sungailiat seperti yang diharapkan dan diusulkan yaitu merancang dan mengoptimalisasikan aplikasi yang sudah terkomputerisasi.

Beberapa contoh urutan proses bisnis yang terjadi pada sistem berjalan dapat dilihat pada activity diagram berikut ini :

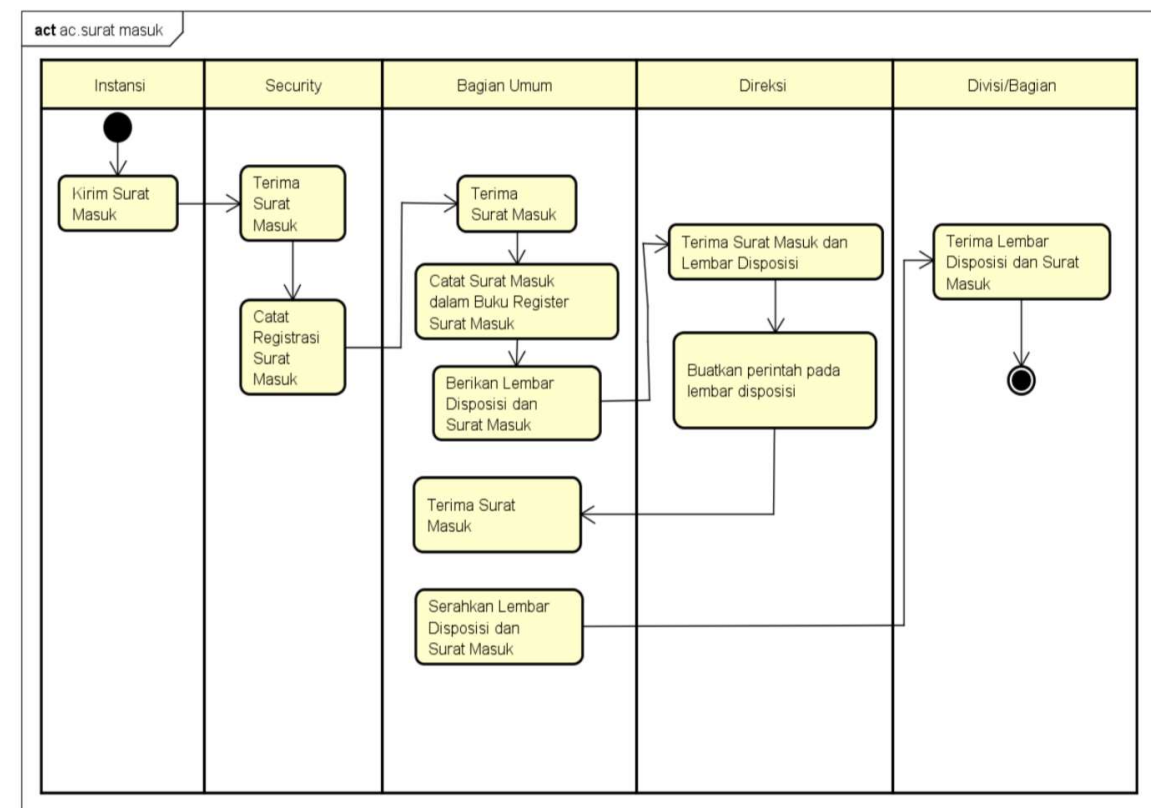

Gambar 1. Diagram Aktifitas (Activity Diagram) Pencatatan Surat_Masuk

Pada gambar activity diagram diatas menjelaskan tentang urutan kegiatan proses bisnis pendataan Surat Masuk pada sistem yang sedang berjalan pada administrasi surat menyurat PT. BPR Sentral Mitra Sejahtera(SMS) Sungailiat saat ini.

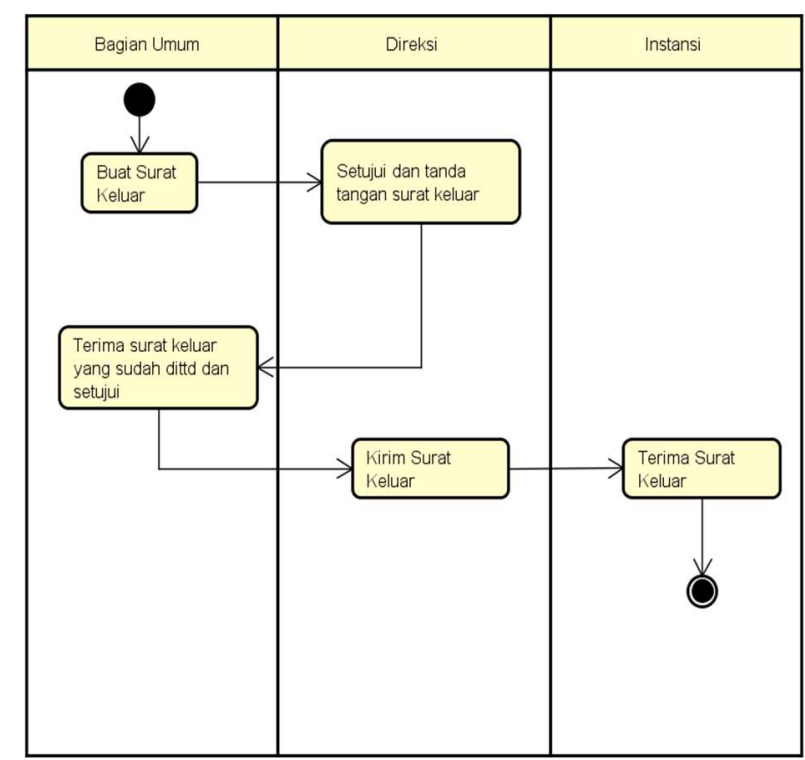

Gambar 2. Diagram Aktifitas Pembuatan Surat_Keluar 
Pada gambar activity diagram diatas menjelaskan tentang urutan kegiatan proses bisnis pembuatan surat keluar sistem berjalan pada Administasi Surat Menyurat Pada PT. BPR Sentral Mitra Sejahtera Sungailiat saat ini.

Kemudian dilanjutkan dengan Diagram Fungsional, seperti rancangan fungsionalitas sistem digambarkan sebagai berikut ini.

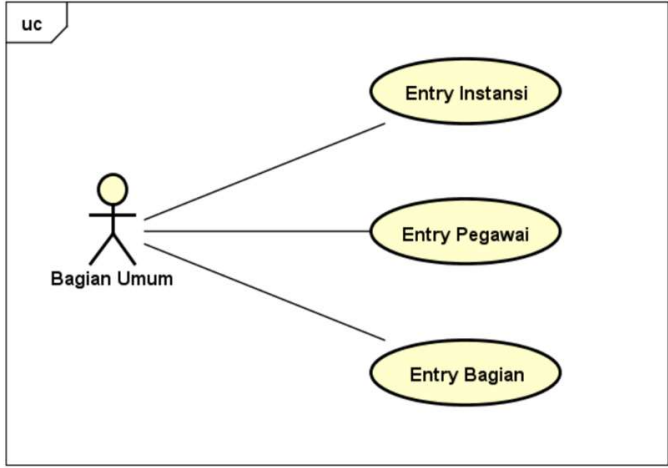

(a)

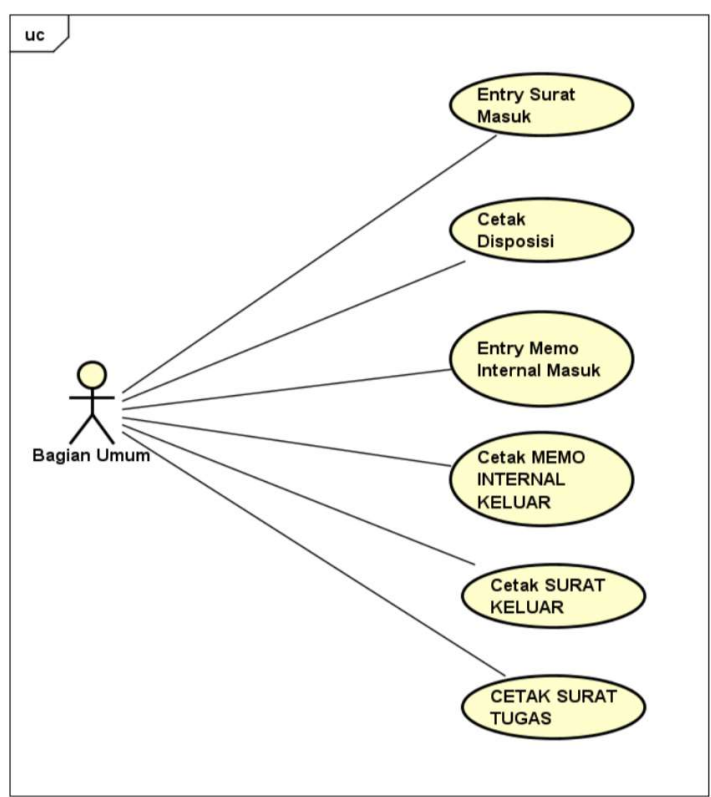

(b)

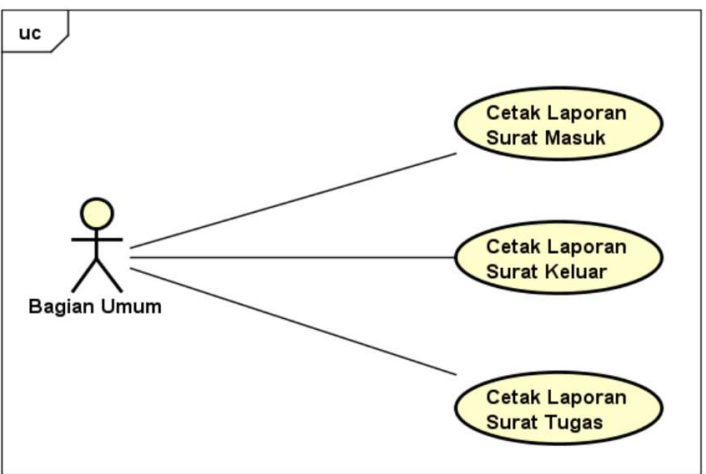

(c)

Gambar 3. Diagram Fungsional Sistem Usulan (a,b,c)

Pada gambar Use Case Diagram diatas, memperlihatkan proses-proses sistem usulan yang dapat dilakukan pada Optimalisasi Sistem Informasi Surat Menyurat Pada PT. BPR Sentral Mitra Sejahtera Sungailiat yang dilihat dari sudut pandang kebutuhan $u$ ser. 
Berikutnya Diagram Keterhubungan Entitas menggambarkan dan memodelkan hubungan anta entitas yang ada pada system tersebut, sehingga dapat dihasilkan file-file yang akan dibentuk, gambar ERD dapat dilihat dibawah ini.

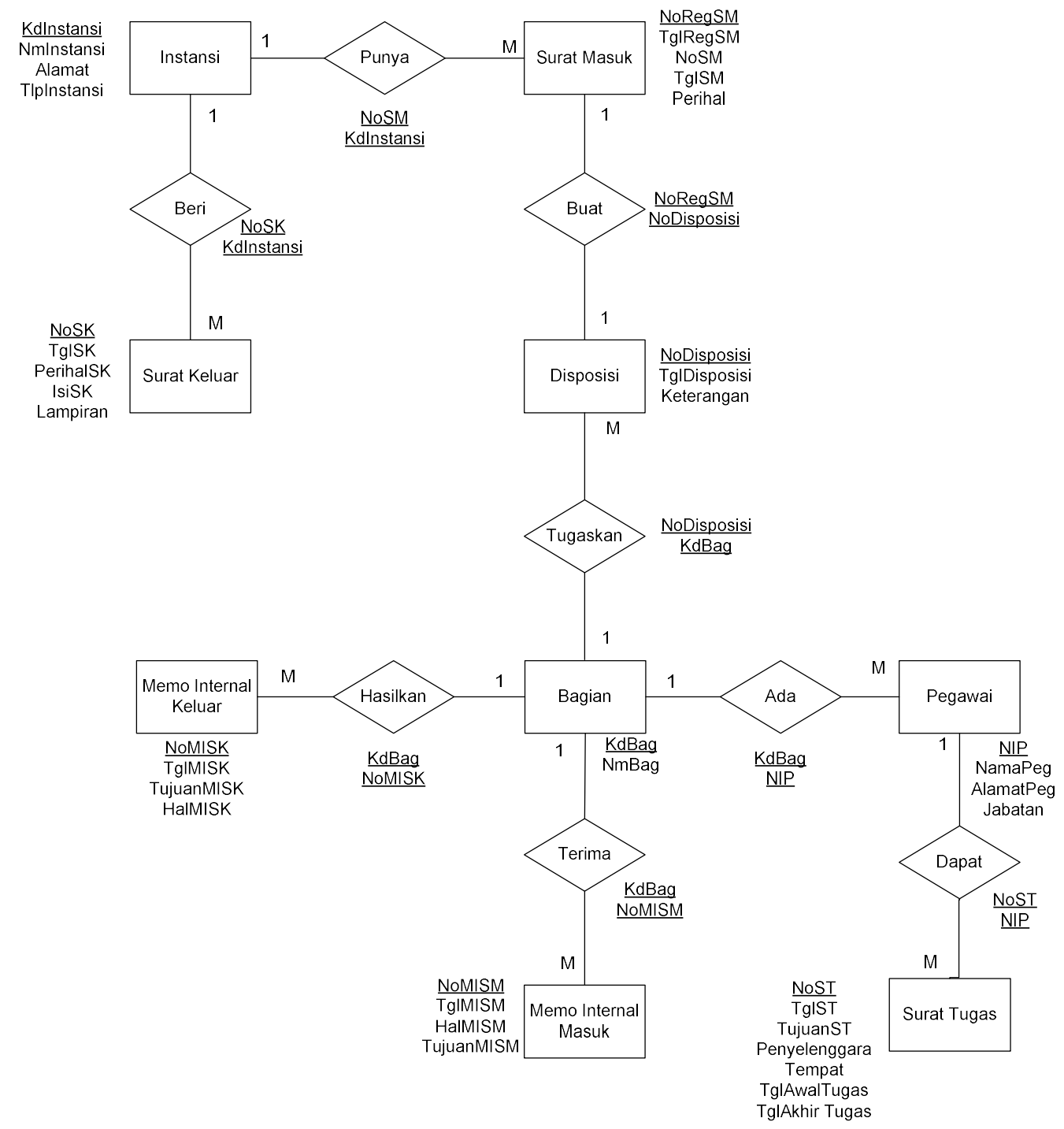

\section{Gambar 4. Diagram Keterhubungan Entitas}

Pada Diagram Keterhubungan Entitas diatas diperlihatkan hubungan antar entitas yang terlibat didalam Optimalisasi Sistem Informasi Surat Menyurat Pada PT. BPR Sentral Mitra Sejahtera (SMS) Sungailiat. Selanjutnya dari Diagram Keterhubungan Entitas diatas, ditransformasikan ke LRS, dengan gambar sebagai berikut : 


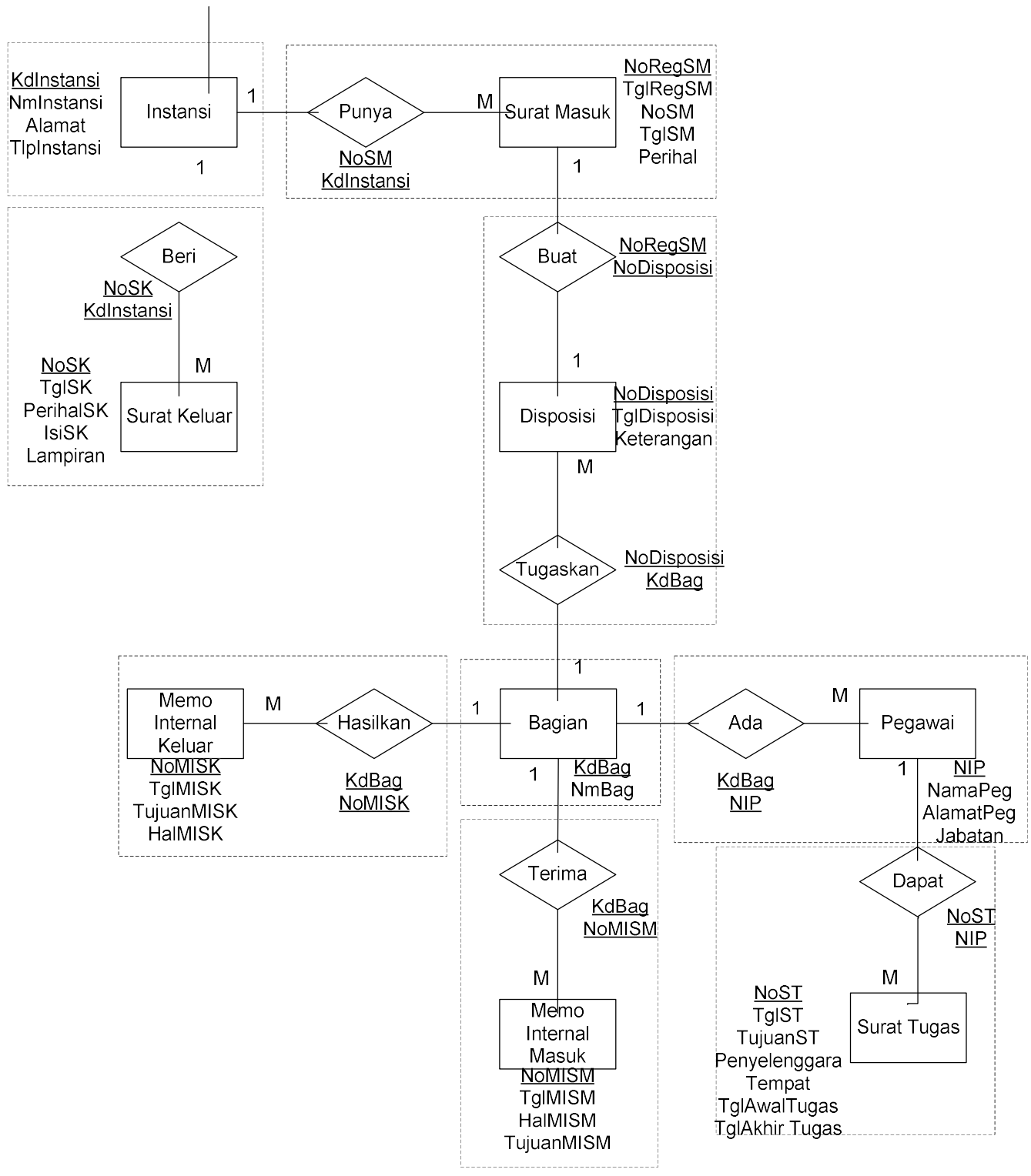

Gambar 5. Transformasi Diagram Keterhubungan Entitas Ke LRS

Pada gambar transformasi Diagram Keterhubungan Entitas ke LRS diatas, digambarkan secara jelas bagaimana cara mengahasilkan LRS sesuai dengan pedoman pentransformasiannya, dimana sangat tergantung pada tingkat derajat kardinalitasnya

Kemudian didapatlah logical record structure yang nantinya akan digunakan sebagai referensi pembuatan tabel-tabel seperti gambar dibawah ini : 


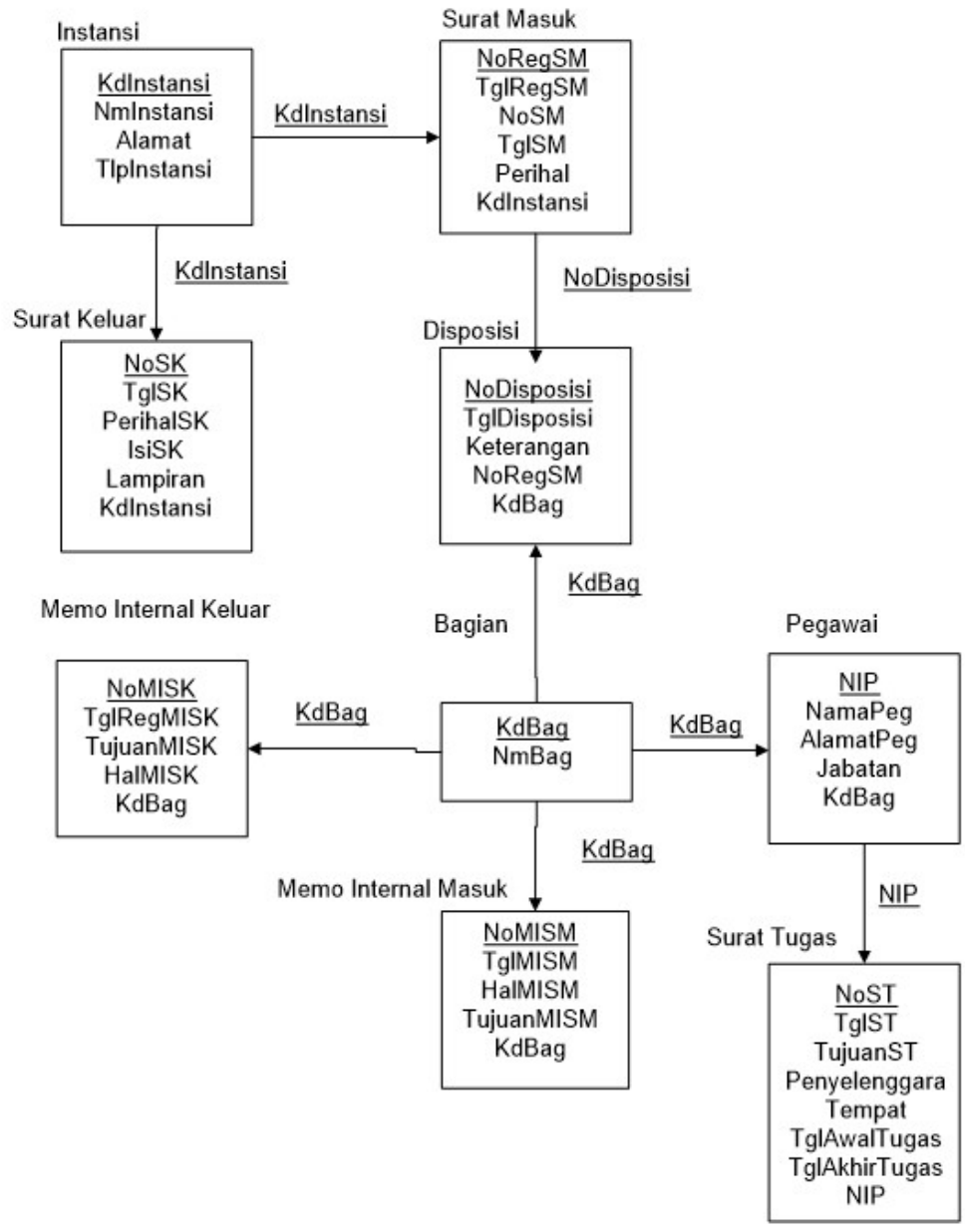

\section{Gambar 6. Logical Record Structure (LRS)}

Dari gambar diatas, dihasilkan bentuk Logical Record Structure yang sudah bisa dijadikan sebagai acuan dalam pembuatan table-tabel, sehingga membentuk suatu sistem database yang saling terintergrasi membentuk aplikasi sistem.

Dari penggambaran LRS diatas, dihasilkan tabel-tabel pada sistem ini dijabarkan dengan jelas dalam bentuk beberapa contoh tabel dibawah ini:

a. Tabel Instansi digunakan untuk menyimpan data-data instansi, yang dapat dilihat di tabel 1 berikut ini.

Tabel 1. Tabel instansi

\begin{tabular}{cccc}
\hline KdInstansi & NmInstansi & Alamat & TlpInstansi \\
\hline PK & & & \\
\hline
\end{tabular}

b. Tabel Surat_Keluar digunakan untuk menyimpan data transaksi surat_keluar, yang dapat dilihat di tabel 2 berikut ini.

Tabel 2. Tabel surat keluar

\begin{tabular}{|c|c|c|c|c|c|}
\hline NoSK & TglSK & PerihalSK & IsiSK & Lampiran & KdInstansi \\
\hline PK & & & & & FK \\
\hline
\end{tabular}

c. Tabel Registrasi Surat_Masuk digunakan untuk menyimpan data transaksi surat_masuk, seperti tabel di tabel 3 berikut ini.

Tabel 3. Tabel registrasi surat masuk

\begin{tabular}{cccccc}
\hline NoRegSM & TglRegSM & NoSM & TglSM & Perihal & KdInstansi \\
\hline PK & & & & & FK \\
\hline
\end{tabular}


d. Tabel Disposisi ini digunakan untuk menyimpan data-data hasil pendisposisian surat_masuk, yang dapat dilihat di tabel 4 berikut ini.

Tabel 4. Tabel disposisi

\begin{tabular}{cccccc}
\hline NoDisposisi & TglDisposisi & Keterangan & TglSM & NoRegSM & KdBag \\
\hline PK & & & & FK & FK \\
\hline
\end{tabular}

e. Tabel 5 digunakan untuk menyimpan data-data bagian.

Tabel 5. Tabel Bagian

\begin{tabular}{cc}
\hline KdBag & NmBag \\
\hline PK & \\
\hline
\end{tabular}

Sedangkan aplikasi rancangan layar yang sudah dirancang untuk aplikasi sistem inofrmasi ini adalah sebagai berikut:

Tabel 6. Daftar rancangan layar

\begin{tabular}{llll}
\hline No. & Nama Rancangan Layar & No. & Nama Rancangan Layar \\
\hline 1 & Entry Instansi & 8 & Entry Memo Internal Masuk \\
2 & Entry Pegawai & 9 & Cetak Memo Internal Keluar \\
3 & Entry Bagian & 10 & Cetak Surat Tugas \\
4 & Entry Data Masuk & 11 & Cetak Laporan Surat Keluar \\
5 & Cetak Surat Keluar & 12 & Cetak Laporan Surat Masuk \\
6 & Cetak Disposisi & 13 & Cetak Laporan Surat Tugas \\
7 & Cetak Laporan Polis Tertanggung & & \\
\hline
\end{tabular}

Sedangkan beberapa contoh rancangan layar yang dihasilkan dari aplikasi sistem informasi usulan tersebut, diperlihatkan pada gambar rancangan layar dibawah ini :

a. Rancangan Layar Entry Instansi

Digunakan untuk menginput data-data instansi

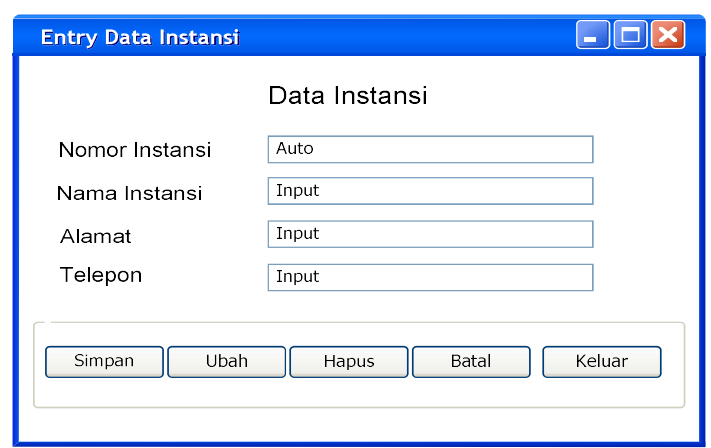

Gambar 7. Rancangan Layar Entry Instansi

Rancangan layar diatas untuk menginput data-data instansi yang mengirimkan surat masuk dan yang menerima surat keluar.

b. Rancangan Layar Entry Surat Masuk

Rancangan layar ini digunakan untuk mengentri data surat yang masuk ke BPR Sentral Mitra Sejahtera Sungailiat. 


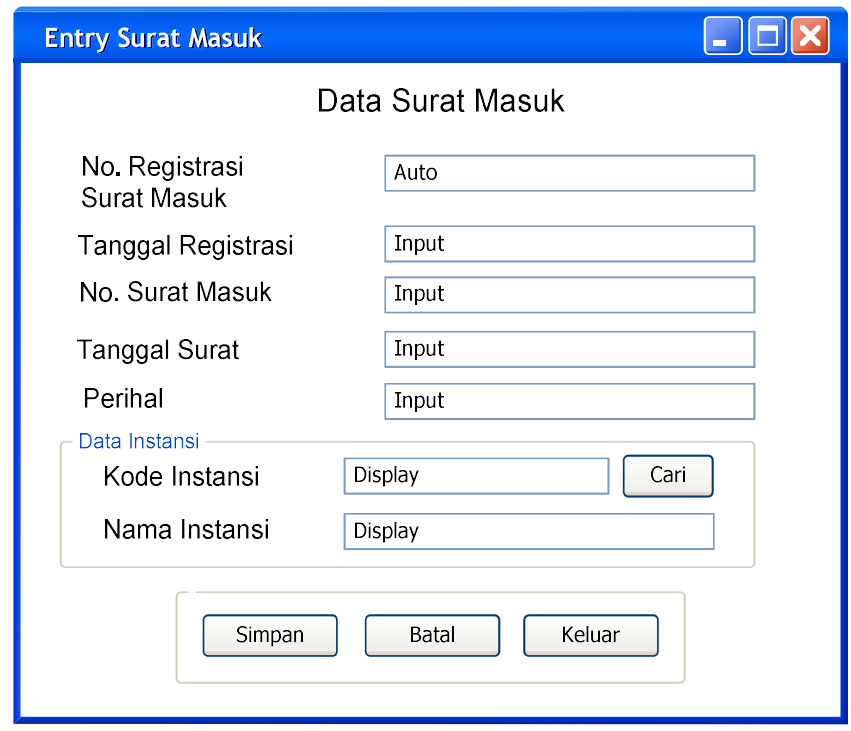

Gambar 8. Rancangan Layar Entry Surat Masuk

Rancangan layar diatas berfungsi untuk mengentri data-data surat yang masuk yang akan dilanjutkan dengan pendisposisian.

c. Rancangan Layar Cetak Disposisi

Rancangan layar ini untuk mencetak disposisi setelah data surat masuk didisposisikan oleh pimpinan.

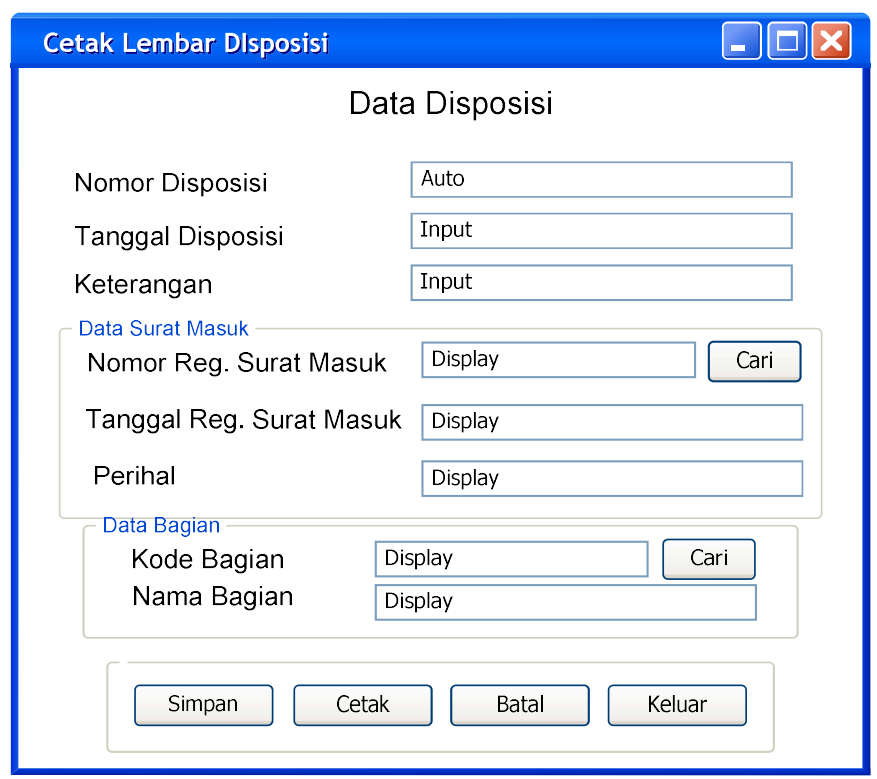

Gambar 9. Rancangan Layar Cetak Disposisi

Rancangan layar diatas berfungsi untuk mencetak disposisi yang datanya sudah dientri pada surat masuk.

d. Rancangan Layar Cetak Surat Tugas

Tujuan Rancangan layar ini untuk mencetak surat tugas yang akan diberikan kepada pegawai sebagai bukti penugasan. 


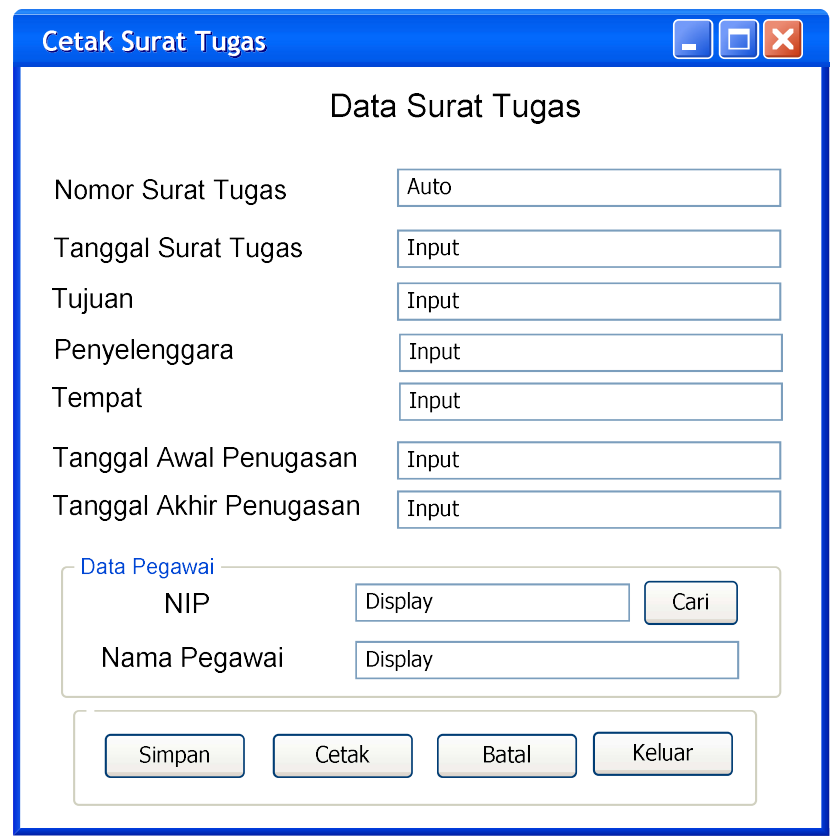

Gambar 10. Rancangan Layar Cetak Surat Tugas

Tujuan pembuatan Rancangan layar diatas yaitu untuk mencetak surat tugas yang akan diberikan kepada pegawai sebagai bukti penugasan pegawai.

\section{KESIMPULAN}

Dengan menerapkan pengelolaan administrasi surat menyurat yang sudah terkomputerisasi dan terseistem pada PT. BPR Sentral Mitra Sejahtera Sungailiat, maka dapat ditarik kesimpulan sebagai berikut:

a. Pekerjaan staf admin menjadi lebih mudah dan ringan

b. Keakuratan hasil pengolahan data atau informasi yang berkualitas.

c. Mengurangi Human Error.

d. Penyajian informasi dilakukan dapat diakses oleh pimpinan dan staf bagian. Baik itu ditambah, dihapus, diubah atau diperbaharui sesuai dengan kebutuhan yang akan disajikan untuk digunakan demi kelancaran sistem.

e. Pembuatan dan penyajian laporan surat menyurat dapat lebih cepat, tepat dan akurat.

Adapun beberapa saran agar Optimalisasi Sistem Informasi Surat Menyurat Pada PT. BPR Sentral

Mitra Sejahtera Sungailiat ini agar dapat berjalan lebih baik, responsif, efisien dan efektif adalah sebagai berikut:

a. Cek dulu kebenaran data yang akan di input agar menghasilkan output/ informasi yang berkualitas dan terjamin.

b. back-up secara rutin semua data surat menyurat dan harus ada pengawasan data.

c. Tersedianya tata cara / standar operasional yang jelas dan rinci tentang sistem administrasi surat menyurat

d. Maintenance secara rutin.

e. Perlunya pelatihan bagi para staf adminitrasi surat menyurat untuk mengatasi masalah yang terjadi Sistem Informasi Surat Menyurat pada PT. BPR Sentral Mitra Sejahtera(SMS) Sungailiat, agar system yang digunakan dapat berjalan dengan semestinya.

\section{DAFTAR PUSTAKA}

[1] Masriadi, 2018. "Perancangan Aplikasi Administrasi Surat Menyurat Berbasis Desktop Pada Andalusia Library And knowledge Center UPI YPTK Padang”. Jurnal KomTekInfo Vol.9, No.1, Juni 2018.

[2] Nita YS, Fera, 2018. "Sistem Informasi Administrasi Surat masuk dan Surat Keluar Pada Biro Rektorat Universitas Katolik Santo Thomas Medan”, Jurnal MEANS, Vol.3, No. 1, Juni 2018.

[3] Fajri Ramadhan, Muhammad, Lusi Fajarita, 2018 "Pembuatan Aplikasi Sistem Informasi Administrasi Surat Menyurat Studi Kasus : Kesekretariatan BEM Universitas Budi Luhur”, Jurnal IDEALIS Vol.1, No.1, Maret 2018. 
[4] Srimandha Rifai, Okta, DKK, 2018, "Perancangan Sistem Informasi Pengelolaan Administrasi Surat Menyurat Di Kantor Desa Sumberdem Kecamatan Wonosari Kabupaten Malang”, Seminar Nasional Sistem Informasi 2018 Fakultas Teknologi Informasi UNMER Malang, 2018.

[5] Ericson, Effiyaldi, 2018. "Analisis dan Perancangan Sistem Informasi Pengelolaan Administrasi Surat Menyurat Berbasis Web Pada Dinas Pekerjaan Umum dan Perumahan Rakyat Propinsi Jambi”. Jurnal Manajemen Sistem Informasi, Vol.3, No.4, Desember 2018.

[6] Lestariningsih, Endang, Dkk, 2015. "Rancang Bangun E-Office Administrasi Surat Di Bagian Humas Universitas STIKUBANG Semarang”, Jurnal Dinamika Informatika, Vol.7 No.2, Oktober 2015.

[7] Anggraini, Defi, Siska Iriani, 2016. "Sistem Informasi Pengarsipan Surat Masuk Dan Surat Keluar Pada Kantor Kecamatan Pringkuku”, Indonesian Journal on Networking and Security, Vol.4, No.2, 2016.

[8] Ariana, I Kadek, 2015. "Sistem Informasi Administrasi Surat Berbasis Web Pada Kantor Camat Gianyar", Jurnal Online Sistem Informasi, Vol.1 No.1, 2015.

[9] Dendi Rachmatsyah, Agus, Datia, 2017. "Perancangan Sistem Informasi Administrasi Surat Berbasis Desktop Pada Kantor Notaris Hoiril Masuli, Sh, M.Kn”, Jurnal Sisfokom, Vol.6 No. 2, September 2017.

[10] Irfan, Marina 2017. “Sistem Informasi Surat Menyurat dikantor kelurahan Deli Tua.”, Jurnal Sekolah Tinggi Teknik Harapan Medan, Medan, 2017. 